\title{
Differences in Free Sterols Content and Composition Associated With Somatic Embryogenesis, Shoot Organogenesis and Calli Growth of Flax
}

Ana Cunha and Manuel Fernandes Ferreira*

Department of Biology, University of Minho, Campus de Gualtar, 4719 Braga Codex, PORTUGAL

(* to whom the correspondence should be addressed)

Key words: free sterols, lipid content, in vitro tissue culture, somatic embryos, Linum usitatissimum.

\begin{abstract}
A single medium was used for induction of somatic embryogenesis and shoot organogenesis from flax hypocotyls. With this system, a comparative study was performed to determine the free sterols content and composition in non-organogenic, shoot organogenic and embryogenic calli as well as in regenerated shoots and somatic embryos grown under the same hormonal supplementation. The induction of somatic embryogenesis and shoot organogenesis of flax was associated with an increase of total sterols in the competent calli and an increased ratio of stigmasterol to $\beta$-sitosterol in derived embryos and shoots. On the contrary, in non-organogenic calli, the ratio stigmasterol to $\beta$-sitosterol decreased during the exponential growth phase due to a drastic rise in the $\beta$-sitosterol content. This effect as well as the calli growth were higher with $0.5 \mathrm{mg} / 1$ 2,4-D than with $0.6 \mathrm{mg} / 1 \mathrm{IBA}$.
\end{abstract}

Abbreviations: 2,4-D - 2,4 - Dichlorophenoxyacetic acid; C - Non-organogenic calli; E.C. - Embryogenic calli; GC- Capillary gas chromatography; IBA - Indole-3-butyric 
acid; KIN - Kinetin; NAA - $\alpha$-naphthaleneacetic acid, S - Developing shoots; S.E. somatic embryos; S.C. - Shoot organogenic calli and ZEA - Zeatin.

\section{INTRODUCTION}

Notwithstanding a vast lore of information on strategies of in vitro induction and development of organogenesis and somatic embryogenesis, knowledge of the inherent fundamental biology remains scanty. Several studies have been undertaken, however, to sequence the developmental events in order to understand the process of induction and development of somatic embryogenesis (1) as well as shoot induction and organogenesis (2).

Somatic embryos of some species have been shown to accumulate storage products similarly to zygotic embryos $(3,4,5)$. According to Joy et al. (6), during the early stages of the development of Picea glauca somatic embryos, polysaccharides, mostly starch, are produced as storage products, whereas during later stages, lipids followed by proteins accumulate. The lipid accumulation by somatic embryos of Theobroma cacao has been extensively studied $(3,7,8)$, and lipids synthesized in somatic embryos have fatty acid and triglyceride compositions similar to those of in vitro maturing zygotic embryos. Lipid accumulation in the form of triglycerides seems to be mostly responsible for the increase in the content of total lipids occurred during the maturation of either zygotic embryos (9) or somatic embryos $(5,10,11)$. A rapid increase in the formation of polar lipids and phospholipids in the period just before the embryoids become visible has also been reported (11 and references therein). According to the same authors the increase in phospholipid synthesis is correlated with the increased rate of cell division. Lipid changes associated with shoot organogenesis have also been reported (2 and references therein, 12,13). Phytosterols are important components of cellular membranes $(14,15)$. The production of plant sterols in in vitro cultures has been extensively reported $(16,17,18,19,20,21,22,23)$, however, studies on the 
synthesis and accumulation of phytosterols associated with the induction and development of somatic embryos and shoot organogenesis have not been carried out. This paper reports a comparative study on the content and composition of free sterols in non-morphogenic calli as well as embryogenic and shoot organogenic competent calli, somatic embryos and early developing shoots of flax.

\section{MATERIALS AND METHODS}

\section{Plant material and culturing conditions}

Flax seeds were immersed in $70 \%$ ethanol, surface sterilized in a $20 \%$ calcium hypochlorite solution for $10 \mathrm{~min}$. and then thoroughly washed in sterile water. The seeds were allowed to germinate in vitro on MS medium (24) containing 2\% sucrose and solidified with $0.8 \%$ agar (Iberagar, J. M. Vaz Pereira, Lisboa Portugal) after pH adjustment to 5.7. All the biological material was cultured in a growth chamber under a $16 \mathrm{~h}$ light photoperiod and $22^{\circ} \mathrm{C}$. Three types of MS medium were used for germination: MS0 - medium without hormonal supplementation; MS1 - supplemented with $0.6 \mathrm{mg} / 1 \mathrm{IBA}+0.5 \mathrm{mg} / \mathrm{KIN}$ and MS2 - supplemented with $0.5 \mathrm{mg} / 1$ 2,4-D + 0.5

mg/l ZEA. All the hormones were autoclaved with the medium. Hypocotyl segments were cut off seedlings grown on MS0 medium for 3 to 5 weeks and used as primary explants for both calli induction and morphogenic differentiation.

Two different combinations of growth regulators were selected to study the production of free sterols by non-morphogenic calli during a 49 days growth period: MS2 and MS3 medium $(0.6 \mathrm{mg} / 1 \mathrm{IBA}+0.5 \mathrm{mg} / 1 \mathrm{ZEA})$. This study was performed using nonmorphogenic, well-established 5 month old calli, maintained under the environmental conditions above stated by subcultures of 5-6 weeks interval. After subculture, samples of eight calli were randomly harvested at $0,3,7$ days and once a week for seven weeks. The sampled calli were freeze dried before determination of biomass dry weight and 
then processed for lipid extraction. The production of free sterols by different types of plant tissues induced in vitro was also assessed. After an eight week period on MS medium supplemented with $0.4 \mathrm{mg} / 1$ 2,4-D + $1.6 \mathrm{mg} / \mathrm{l} \mathrm{ZEA}$, which is a non-exclusive embryogenic medium (25), non-organogenic calli (C), shoot organogenic calli (S.C.) and embryogenic calli (E.C.), all at the stationary phase, were harvested separately. At the end of the 8th week, embryogenic calli differentiated a maximum, although variable, number of somatic embryos, the majority of which, as described before (25) showed a conspicuous shoot pole and two cotyledons. The meristematic primordia that differentiated organogenic shoots did not exhibit cotyledons. The calli that showed differentiation of both somatic embryos and organogenic shoots were not considered for this study. The developing shoots (S) as well as somatic embryos (S.E.) were detached with forceps from the respective calli and stored at $-70^{\circ} \mathrm{C}$ before lipid extraction.

\section{Extraction of the lipid fraction and quantitative analysis of the main sterols by GC}

Seedlings, calli, somatic embryos and organogenic shoots sampled during the experiments were freeze dried at $4 \mu$ bar (Alpha 2-4 LDC-1m) for $48 \mathrm{~h}$. Total lipids were extracted from powdered material by $\mathrm{n}$-hexane in a Soxhlet apparatus for $48 \mathrm{~h}$. The amount of dry plant material analyzed varied with the type of tissue. For lipid extraction, $3 \mathrm{~g}$ of seeds, 200 to $800 \mathrm{mg}$ of calli and seedlings and 50 to $60 \mathrm{mg}$ of somatic embryos and shoots were used per replicate. After evaporation of the solvent by a rotary evaporator and nitrogen flow, samples of the lipid extracts were derivatized by trimethylsilylation for $1 \mathrm{~h}$ at $55^{\circ} \mathrm{C}$ with cholesterol as an internal standard. The amount of lipid extract used for derivatization was $1 \mathrm{~g}$ for seeds and 5 to $10 \mathrm{mg}$ for all other tissues. The sterol trimethylsilyl ethers were analysed with a GC instrument equipped with a flame ionization detector and a BP5 column (25 m, $0.25 \mu \mathrm{m}$ film thickness) using a temperature program from $180^{\circ} \mathrm{C}$ to $280^{\circ} \mathrm{C}\left(5^{\circ} \mathrm{C} / \mathrm{min}\right.$.) followed by an 
isothermal for $20 \mathrm{~min}$. The identification of the sterols was confirmed by using campesterol, stigmasterol and $\beta$-sitosterol as standards.

\section{Statistical analysis}

Mean differences were statistically analyzed running the one way analysis of variance test (ANOVA). Post hoc comparisons were performed with the HSD Tuckey test (Statistica@ 4.1, StatSoft). The non-linear regression analysis was performed with the data analysis KaleidaGraph 3.0.2 package (AbelbecK Software).

Nomenclature: Campesterol $=(24 \mathrm{R})-24$-methylcholest-5-en-3 $\beta$-ol; $\beta$-sitosterol $=(24 \mathrm{R})-$ 24-ethyl-cholest-5-en-3 $\beta$-ol; stigmasterol = (24R)-24-ethyl-5a-cholesta 5,22-dien-3 $\beta$-ol.

\section{RESULTS}

The total lipid and sterol content determined for dry flax seeds, seedlings, calli, somatic embryos and in vitro regenerated shoots are shown in Table 1. Although the total lipid content of these flax seeds was about five-fold over those determined for seedlings, regenerated shoots and somatic embryos and more than ten-fold over those determined for calli, the content of their total free sterols was the lowest (Table 1). A specific sterol content as low as that of seeds was also found in non-organogenic calli (Table 1). Shoot organogenic and embryogenic calli contained sterol contents higher than that of seeds but significantly lower than those found in the respectively derived shoots and somatic embryos (Table 1). Curiously, the content of total lipids measured in embryogenic calli was lower than that found in non-organogenic ones. However, as in the regenerated shoots, the total lipid content in somatic embryos was almost three-fold higher than in embryogenic calli (Table 1). These results show that during the expression of somatic embryogenesis of flax, but not during shoot organogenesis, there is a decrease of total 
lipids in embryogenic competent calli and a concomitant increase of these compounds in the developing embryos. On the other hand, either during the expression of somatic embryogenesis or shoot organogenesis, competent calli accumulated a higher level of free sterols when compared to non-organogenic calli (Table 1).

Table 1 - Total lipid and free sterol content for in vitro grown material and dry flax seeds.

\begin{tabular}{|c|c|c|c|}
\hline Plant material & $\begin{array}{c}\text { Hormonal } \\
\text { supplementation } \\
(\mathrm{mg} / \mathrm{l})\end{array}$ & $\begin{array}{c}\text { Total lipids } \\
\text { (mg/g dry weight) }\end{array}$ & $\begin{array}{c}\text { Free sterols } \\
\text { (mg/g dry weight) }\end{array}$ \\
\hline Dry seeds & 0 & $352.8 \quad(\mathrm{e})$ & $0.94 \quad(d)$ \\
\hline \multirow{3}{*}{ Seedlings } & 0 & $65.3 \quad(a b)$ & 2.24 (a) \\
\hline & 0.5 2,4-D+0.5 ZEA & 93.4 (a) & 1.83 (b) \\
\hline & $0.6 \mathrm{IBA}+0.5 \mathrm{KIN}$ & 62.8 (b) & $1.88 \quad(\mathrm{ab})$ \\
\hline $\begin{array}{c}\mathrm{C} \\
\text { (non-organogenic calli) }\end{array}$ & \multirow{5}{*}{0.4 2,4-D+1.6 ZEA } & $28.1 \quad(\mathrm{c})$ & $1.32(\mathrm{~d})$ \\
\hline $\begin{array}{c}\text { S.C. } \\
\text { (shoot organogenic calli) }\end{array}$ & & 32.3 (cd) & $1.48 \quad(\mathrm{c})$ \\
\hline $\begin{array}{c}\text { E.C. } \\
\text { (embryogenic calli) }\end{array}$ & & $23.6 \quad(d)$ & $1.45 \quad(\mathrm{c})$ \\
\hline $\begin{array}{c}\text { S.E. } \\
\text { (somatic embryos) }\end{array}$ & & $62.1 \quad$ (b) & 2.13 (a) \\
\hline $\begin{array}{c}\text { S } \\
\text { (shoots) }\end{array}$ & & $61.5^{*}$ & $2.1 *$ \\
\hline
\end{tabular}

Seedlings and calli were grown on MS medium with the various hormonal supplementations. Calli used in this study were collected at the stationary growth phase. Results are represented as means of 2-3 replicates. In each column, means followed by the same letters, were not statistically different $(\mathrm{p}>0.05)$.

* No statistics were possible due to the loss of a duplicate. The value obtained was, however, in the range of those obtained for somatic embryos and seedlings which are a similar type of tissue.

Although non-organogenic flax calli resembles seeds and calli derived plantlets resembles seedlings in their total sterol content, there were significant differences in the relative proportions of the sterols. The GC analysis of the lipid fraction revealed that campesterol, stigmasterol and $\beta$-sitosterol were the main free sterols found in all the 
tissues examined (data not shown). Seeds contained the highest proportion of $\beta$ sitosterol (Fig. 1). The ratio of campesterol/stigmasterol/ $\beta$-sitosterol in flax seeds was 0.36/0.12/1.00 (Fig. 1).

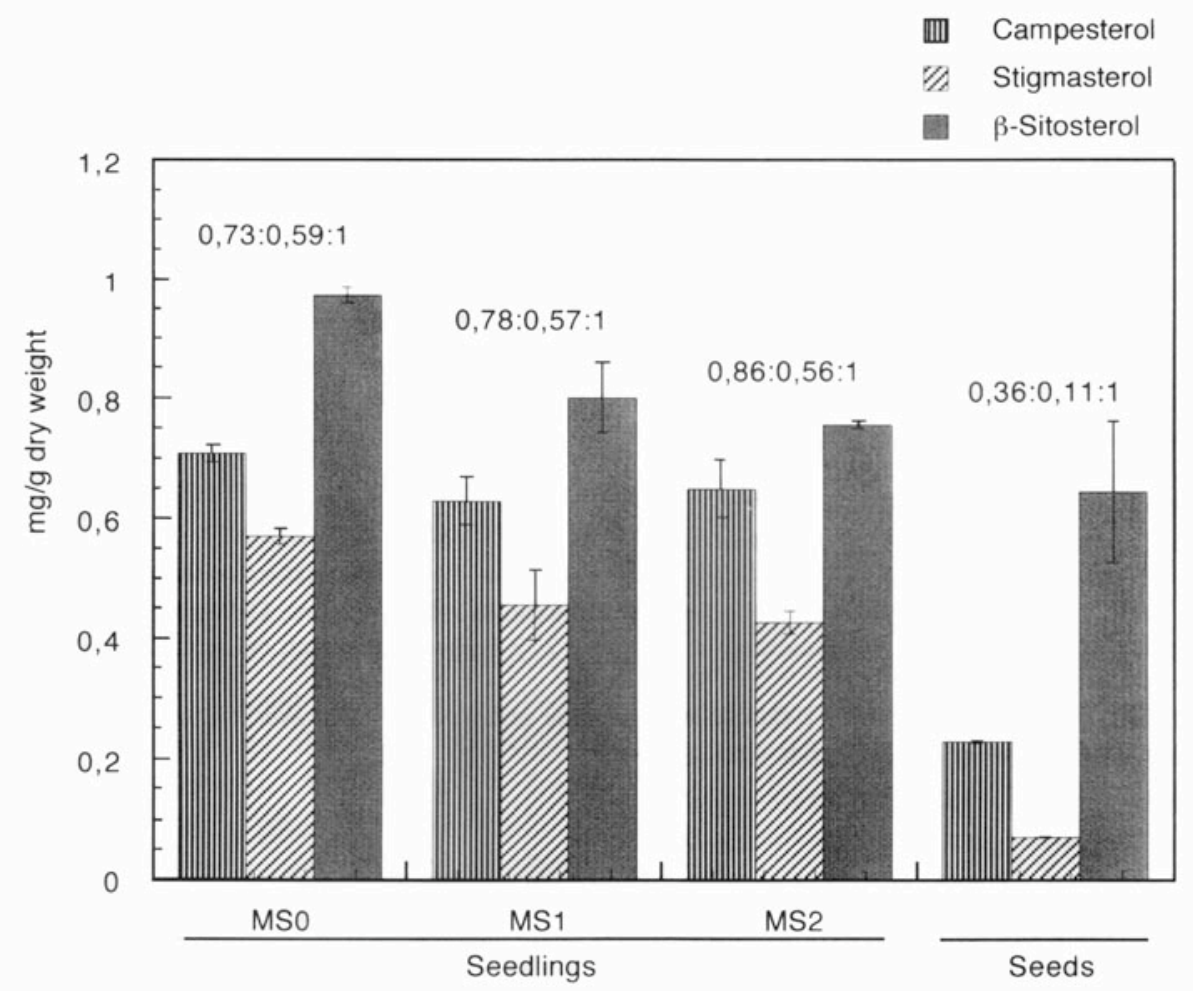

Figure 1 - Specific contents of the main phytosterols found in seedlings and dry seeds of flax. Seedlings were germinated on MS medium supplemented with different growth regulators combinations (MS0: without hormonal supplementation; MS1: $0.6 \mathrm{mg} / 1 \mathrm{IBA}+0.5 \mathrm{mg} / 1 \mathrm{KIN}$ and MS2: $0.5 \mathrm{mg} / 1$ 2,4-D + $0.5 \mathrm{mg} / \mathrm{l} \mathrm{ZEA}$.). Results are means of 3 replicates and standard error bars are shown on the top of each column. The ratios of campesterol:stigmasterol: $\beta$-sitosterol are on the top of each group.

During germination, independently from the medium supplementation, although the content of $\beta$-sitosterol had risen, the synthesis and accumulation of stigmasterol and campesterol increased at higher rates. The ratio of stigmasterol to $\beta$-sitosterol in seedlings was five-fold higher than in seeds while that of campesterol: $\beta$-sitosterol more than doubled. The ratio of campesterol/stigmasterol/ $\beta$-sitosterol in non-organogenic flax calli was $0.56 / 0.37 / 1.00$. In shoot organogenic calli and in embryogenic calli the relative proportions of these sterols were nearly the same (Fig. 2). However, as in seedlings, the 
accumulation of stigmasterol in somatic embryos and regenerated shoots increased at higher rates than $\beta$-sitosterol or campesterol (Fig. 2).

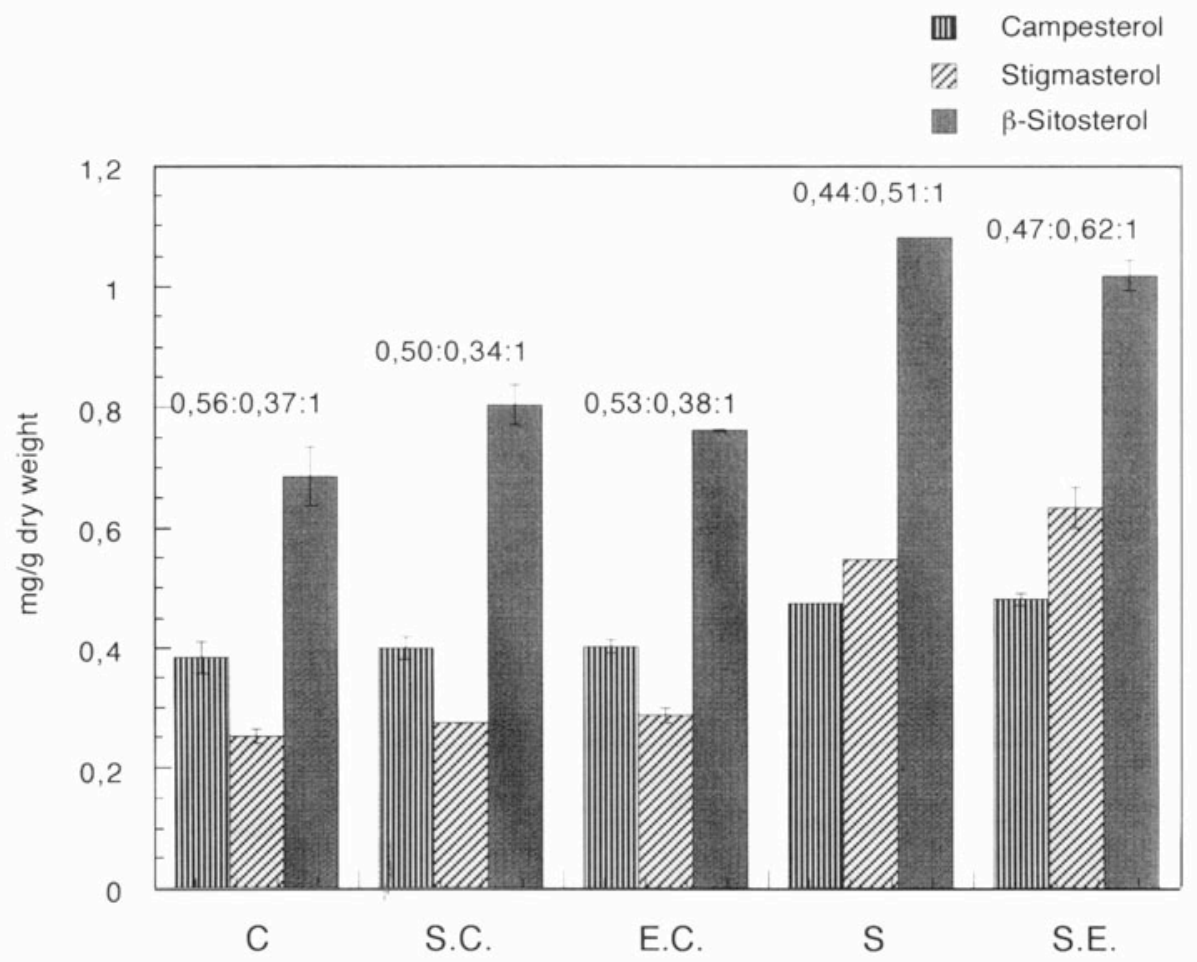

Figure 2 - Specific contents of the main phytosterols produced by non-organogenic calli (C), shoot organogenic calli (S.C.), embryogenic calli (E.C.), shoots (S) and flax somatic embryos (S.E.). This material was induced and grown on MS medium supplemented with $0.4 \mathrm{mg} / 1$ 2,4-D $+1.6 \mathrm{mg} / \mathrm{l}$ ZEA. Results are means of 2-3 replicates and standard error bars are shown on the top of each column. The ratios of campesterol:stigmasterol: $\beta$-sitosterol are on the top of each group.

Non-organogenic calli revealed different growth profiles when grown on MS2 or MS3 media. In the presence of $0.5 \mathrm{mg} / 1$ 2,4-D+ $0.5 \mathrm{mg} / 1$ ZEA (MS2) calli growth followed roughly a sigmoidal curve showing a marked exponential phase (Fig. 3a). With $0.5 \mathrm{mg} / \mathrm{l}$ IBA+ $0.5 \mathrm{mg} / 1$ ZEA (MS3), calli growth was nearly constant over the same period, although more actively during the first 21 days (Fig. 3b). In both cases, there was a significant increase in total sterol content during the first half of the growth period followed by a decrease. $\beta$-Sitosterol accounted for most of that variation. The content of campesterol in calli maintained with $0.6 \mathrm{mg} / \mathrm{l}$ IBA increased from the $3 \mathrm{rd}$ up to the 21 th day decreasing since then. The data was not conclusive for stigmasterol. No significant 
variation in content of these two sterols occurred in calli maintained with $0.5 \mathrm{mg} / 12,4-\mathrm{D}$ (Fig. 3a).
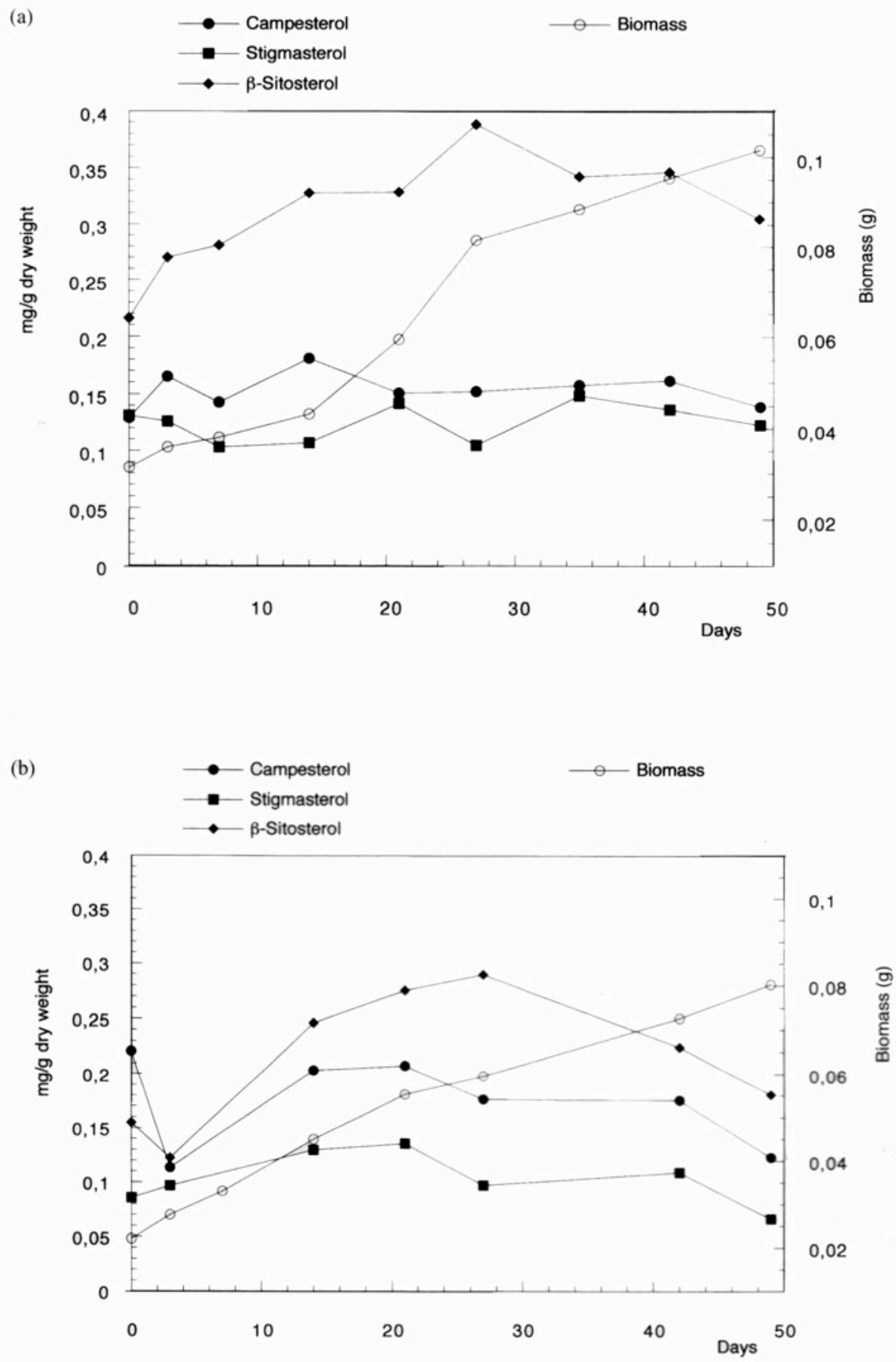

Figure 3a: Free sterols specific contents and biomass profiles of flax calli maintained on MS medium supplemented with $0.5 \mathrm{mg} / 1$ 2,4-D + $0.5 \mathrm{mg} / 1 \mathrm{ZEA}$, during a calli growth period. Eight calli were randomly harvested in each sampling time. b: Free sterols specific contents and biomass profiles of flax calli maintained on MS medium supplemented with $0.6 \mathrm{mg} / \mathrm{l} \mathrm{IBA}+0.5$ 
$\mathrm{mg} / \mathrm{l} \mathrm{ZEA}$, during a calli growth period. Eight calli were randomly harvested in each sampling time.

It seems evident that there is a tight parabolic relationship between $\beta$-sitosterol content and calli growth (Fig. 4). The highest $\beta$-sitosterol content occurred by the end of the most active growth phase. 2,4-D at $0.5 \mathrm{mg} / \mathrm{l}$ was clearly more efficient than IBA at 0.6 $\mathrm{mg} / \mathrm{l}$ on both stimulating calli growth and $\beta$-sitosterol accumulation.

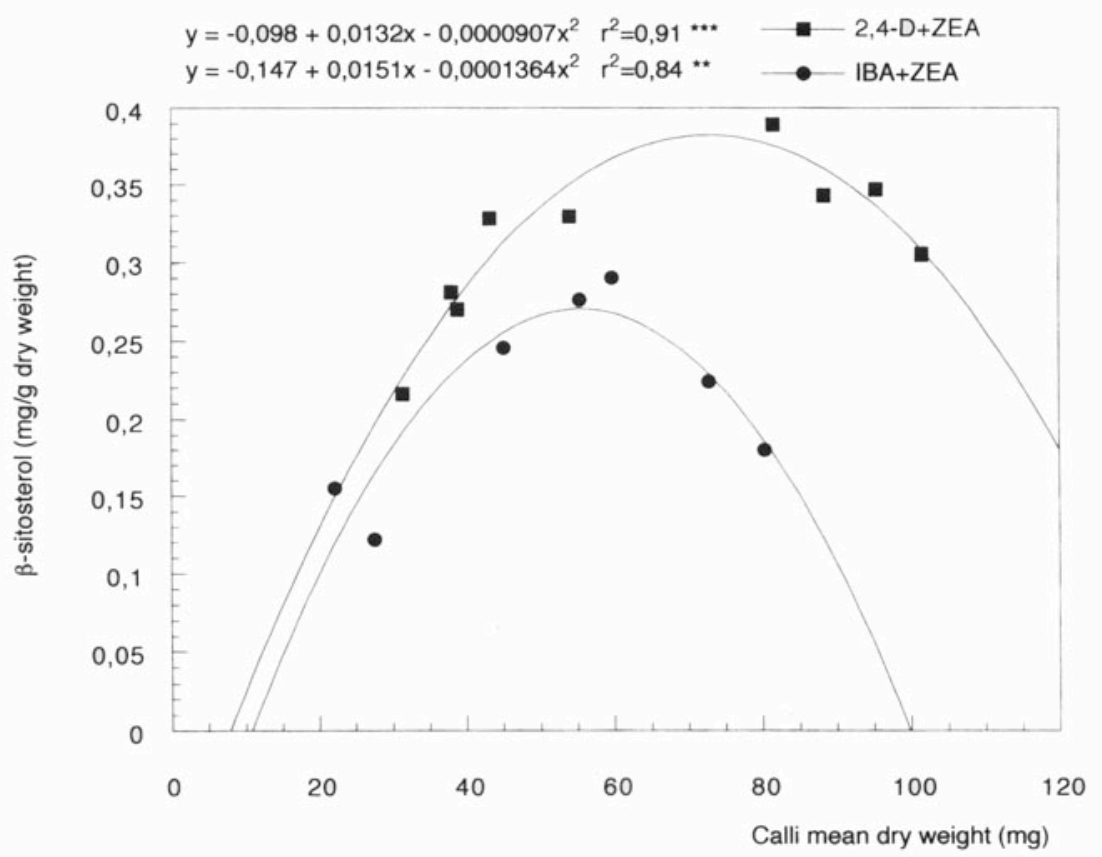

Figure 4 - Specific content of $\beta$-sitosterol as a function of calli dry weight during the growth period. Calli were maintained on MS medium supplemented with two different combinations of auxin plus cytokinin. The equations of the quadratic functions and the respective r-square are represented for each supplementation. The symbols $* *$ and $* * *$ denote respectively that the regression model is highly and very highly significant.

\section{DISCUSSION}

The lower content of total lipids found in embryogenic competent calli relatively to non-organogenic flax calli suggest that the emergence and maturation of somatic 
embryos is related with a decline in total lipids in the source calli. Mhaske and Hazra (5) found that the somatic embryogenesis of peanut, induced from immature leaflets, is preceded by a declining of lipids, namely triglycerides, which continued for four weeks after which these compounds started rising in the emerging embryos.

The biosynthesis of phytosterols, such as phospholipids, is necessary for membrane biogenesis. Plasma membranes have the greatest sterol content and the highest sterol/phospholipid ratio (26). Turnham and Northcote (11) reported a rapid increase in the formation of polar lipids that occurred during embryogenesis of Elaeis guineënsis in the period just before the somatic embryoids became visible. According to these authors, together with the appearance of embryoids there is an increase in the rate of cell division and the increase in the formation of polar lipids may reflect increases in cell membrane phospholipid synthesis. The higher content of total sterols found in shoot organogenic calli and embryogenic calli of flax relatively to non-organogenic ones was also probably associated with membrane biogenesis. The increased content of total sterols recorded for somatic embryos and developing shoots of flax is probably correlated with higher rates of sterol biosynthesis since, according to some authors, the most active site of sterol biosynthesis is located in differentiating tissues $(14,15,27$, 28). High rates of sterol biosynthesis correlated with active membrane biogenesis may also explain the increase of sterol content of the flax seedlings relatively to dry seeds (Table 1) and has been reported for other plant species $(14,15$ and references therein, $23,29)$.

Flax seedlings from seeds germinated on MS medium supplemented with auxins and cytokinins had lower levels of total sterols than seedlings grown on MS medium devoid of phytohormones (Table 1). This may probably be due to toxic effects of the growth regulators as growth of these flax seedlings was significantly reduced when compared with that of seedlings grown on MS0 medium. The toxic effect on sterol production due to overdose levels or antagonism of auxins and cytokinins has been reported for other species $(17,29,30)$. 
According to some authors, seeds and meristematic tissues have high levels of $\beta$ sitosterol and low levels of stigmasterol $(14,15)$. During germination and as a consequence of the seedlings aging, the ratio of stigmasterol to $\beta$-sitosterol increases primarily due to an increase in stigmasterol and not to a decrease in $\beta$-sitosterol $(14,15$, $27,28)$. The results obtained from this study showed that the increase in stigmasterol relatively to $\beta$-sitosterol occurred in the differentiated tissues of seedlings, regenerated shoots and somatic embryos but not in calli. The correlation between the increase in $\beta$ sitosterol content and the most active growth phase of the non-organogenic flax calli supported the idea that $\beta$-sitosterol plays an important role in the high demand of lipid compounds for membrane production. The higher efficiency of 2,4-D relative to IBA, in $\beta$-sitosterol accumulation in growing calli of flax (Figs. 3a,b and 4), may explain the well-known effect of 2,4-D promoting higher calli growth rates than other auxins. Calli of Euphorbia characias grown in the presence of 2,4-D also showed an increase in $\beta$ sitosterol content during the exponential growth phase (18). In Euphorbia characias however, instead of stigmasterol, calli produced avenasterol (28-isofucosterol) which increased sooner and at a higher rate than $\beta$-sitosterol. The results obtained with flax calli are consistent with those of Euphorbia characias when we consider that $\beta$ sitosterol is situated downstream to avenasterol and upstream to stigmasterol in the biosynthetic pathway. Taking into account that meristems, as seeds, have the highest ratios of $\beta$-sitosterol relatively to other sterols $(14,15)$, the occurrence of the highest rate of $\beta$-sitosterol accumulation during the exponential phase, stresses the similarity between non-organogenic calli and meristematic tissues.

The effective interaction with membrane phospholipids requires that sterols have exact molecular configurations that may include a non-substituted C-3 hydroxyl group, a relatively flat molecular structure and at least one double bond in the ring system. Increasing the bulkiness of the C-17 side chain of the sterol molecule increases the difficulty of its incorporation into the membranes of erythrocytes and in liposomes (31) and decreases the effectiveness of the sterol molecule to stabilize membranes (15). 
According to Cooke et al. (32) there is an increase in membrane fluidity and a decrease in the membrane proton-pumping activity in plasma membrane vesicles of oat shoots incubated with stigmasterol relatively to membranes incubated with cholesterol. In general, membrane permeability increases in the order: cholesterol $>$ campesterol $>\beta$ sitosterol > stigmasterol $(14,28,31)$. A positive correlation has emerged between the aging, the increase of the ratio stigmasterol to $\beta$-sitosterol, the rise in permeability to water and the decreasing in $\mathrm{Mg}^{2+}$-dependent plasma membrane activity in mung bean seedlings (28). The differences in terms of total free sterols content and ratio of stigmasterol to $\beta$-sitosterol, between calli and in vitro growing seedlings, regenerated shoots and embryos of flax may eventually determine differences in membrane permeability, fluidity and enzyme activity.

\section{Acknowledgements}

The authors are grateful to Eng. António Silva from ERCA-DRAEM who donated the seed material. The Junta Nacional de Investigação Científica e Tecnológica is also acknowledge for a Ph.D. scholarship (BD/2771/93) granted to Ana Cunha.

\section{REFERENCES}

1 M.C. Pedroso and M.S. Pais, Factors controlling somatic embryogenesis. Cell wall changes as an in vivo marker of embryogenic competence. Plant Cell, Tissue and Organ Culture, 43 (1995) 147-154.

2 G.S. Hicks, Shoot induction and organogenesis in vitro: a developmental perspective. In Vitro Cell. Dev. Biol., 30 (1994) 10-15. 
3 J. Janick, D.C. Wright and P.M. Hasegawa, In vitro production of cacao seed lipids. J. Amer. Soc. Hort. Sci., 107 (5) (1982) 919-922.

4 L. Kong and E.C. Yeung, Development of white spruce somatic embryos: II. Continual shoot meristem development during germination. In Vitro Cell. Dev. Biol., 28 (1992) 125-131.

5 V.B. Mhaske and S. Hazra, Appearance of storage lipid (triglycerides) in somatic embryos of peanut (Arachis hypogaea L.). In Vitro Cell. Dev. Biol., 30P (1994) 113-116.

6 R.W. Joy, E.C. Yeung, L. Kong and T. Thorpe, Development of white spruce somatic embryos: I. Storage product deposition. In Vitro Cell. Dev. Biol., 27 (1991) 32-41.

7 V.C. Pence, P.M. Hasegawa and J. Janick, Sucrose-mediated regulation of fatty acid composition in asexual embryos of Theobroma cacao. Physiol. Plant., 53 (1981) 378-384.

8 D.C. Wright, A.K. Kononowicz and J. Janick, Factors affecting in vitro fatty acid content and composition in asexual embryos of Theobroma cacao. J. Amer. Soc. Hort. Sci., 109 (1) (1984) 77-81.

9 C.H. Tsai and J.E. Kinsella, Tissue culture of cocoa bean (Theobroma cacao. L.): changes in lipids during maturation of beans and growth of cells and calli in culture. Lipids, 16 (8) (1981) 577-582. 
10 R. Schuchmann and E. Wellmann, Somatic embryogenesis of tissue cultures of Papaver somniferum and Papaver orientale and its relationship to alkaloid and lipid metabolism. Plant Cell Reports, 2 (1983) 88-91.

11 E. Turnham and D.H. Northcote, The incorporation of $\left[1-{ }^{14} \mathrm{C}\right]$ acetate into lipids during embryogenesis in oil palm tissue cultures. Phytochemistry, 23 (1) (1984) 3539.

12 K. Manoharan, R. Prasad and S. Guha-Mukherjee, Greening and shootdifferentiation related lipid changes in callus cultures of Datura innoxia. Phytochemistry, 26 (2) (1987) 407-410.

13 M. Williams, D. Francis, A.C. Hann and J.L. Harwood, Changes in lipid composition during callus differentiation in cultures of oilseed rape (Brassica napus L.). Journal of Experimental Botany, 42 (245) (1991) 1551-1556.

14 C. Grunwald, Plant sterols. Ann. Rev. Plant Physiol., 26 (1975) 209-236.

15 C. Grunwald, Steroids, in: E.A. Bell and B.V. Charlwood (Eds.), Secondary Plant Products, Encyclopedia of Plant Physiology, New Series, Vol. 8, Springer Verlag, 1980, pp. 221-254.

16 S.J. Stohs and H. Rosenberg, Steroids and steroid metabolism in plant tissue cultures. Lloydia, 38 (3) (1975) 181-194.

17 M. Fernandes-Ferreira, J.M. Novais and M.S.S. Pais, Hormonal control of triterpenols synthesis in Euphorbia characias calli. Bioresource Technology, 39 (1992a) 31-37. 
18 M. Fernandes-Ferreira, M.S.S. Pais and J.M. Novais, The effects of medium composition on biomass, sterols and triterpenols production by in vitro cultures of Euphorbia characias . Bioresource Technology, 42 (1992b) 67-73.

19 M. Fernandes-Ferreira, J.M. Novais and M.S.S. Pais, Euphorbia characias L.: in vitro culture and the production of sterols, triterpenols, and hydrocarbon-like compounds, in: Y.P.S. Bajaj (Ed.), Biotechnology in Agriculture and Forestry, Medicinal and Aromatic Plants VII, Vol. 28, Springer Verlag, 1994, pp. 214-235.

20 P. Schmitt, T. Gaspar and D. Hagège, Sterol composition of normal and habituated sugarbeet callus (Beta vulgaris L. Altissima). In Vitro Cell. Dev. Biol., 30P (1994) $1-3$.

21 L. Dyas, D.R. Threlfall and L.J. Goad, The sterol composition of five plant species grown as cell suspension cultures. Phytochemistry, 35 (1994) 655-660.

22 M.L. Suardi, S. Bernasconi, F. Pellizoni and M.L. Racchi, In vitro cultures of Solanum malacoxylon Sendt.: nutritional requirements and sterol production. Plant Cell, Tissue and Organ Culture, 36 (1994) 9-14.

23 D. Guo, M. Venkatramesh and D.W. Nes, Developmental regulation of sterol biosynthesis in Zea mays. Lipids, 30 (3) (1995) 203-219.

24 T. Murashige and F. Skoog, A revised medium for rapid growth and bioassays with tobacco tissue cultures. Physiol. Plant., 15 (1962) 473-497. 
25 A. Cunha and M. Fernandes-Ferreira, Somatic embryogenesis, organogenesis and callus growth kinetics of flax (Linum usitatissimum L.). Plant Cell, Tissue and Organ Culture, (in press).

26 L.J. Goad, Phytosterols, in: P.M. Dey and J.B. Harborne (Eds.), Methods in Plant Biochemistry, Vol. 7, Academic Press, 1991, pp. 369-434.

27 J.M.C. Geuns, Variations in sterol composition in etiolated mung bean seedlings. Phytochemistry, 12 (1973) 103-106.

28 V.M. Stallaert and J.M.C. Geuns, Phospholipid and free sterol composition of hypocotyl plasma membranes of ageing mung bean seedlings. Phytochemistry, 36 (1994) 1177-1180.

29 G.B. Lockwood and K.R. Brain, Influence of hormonal supplementation on steroid levels during callus induction from seeds of Trigonella foenumgraecum. Phytochemistry, 15 (1976) 1655-1660.

30 K.R. Brain and G.B. Lockwood, Hormonal control of steroid levels in tissue cultures from Trigonella foenumgraecum. Phytochemistry, 15 (1976) 1651-1654.

31 J.M.C. Geuns, Regulation of sterol biosynthesis in etiolated mung beans hypocotyl sections. Phytochemistry, 14 (1975) 975-978.

32 D.T. Cooke, R.S. Burden, C.S. James, T. Seco and B. Sierra, Influence of sterols on plasma membrane proton-pumping ATPase activity and membrane fluidity in oat shoots. Plant Physiol. Biochem., 32 (1994) 796-773. 